\title{
Maternal Reading Self-Efficacy Associated with Perceived Barriers to Reading
}

\author{
Joyce Lin, Stephanie M. Reich, Sabrina Kataoka, and George Farkas \\ School of Education, University of California, Irvine, 3200 Education Building, Irvine, CA 92697-5500, USA \\ Correspondence should be addressed to Joyce Lin; joycel6@uci.edu
}

Received 26 September 2014; Accepted 16 December 2014

Academic Editor: Kevin J. Riggs

Copyright (C) 2015 Joyce Lin et al. This is an open access article distributed under the Creative Commons Attribution License, which permits unrestricted use, distribution, and reproduction in any medium, provided the original work is properly cited.

\begin{abstract}
Although early reading practices impact a host of child literacy, language, and school outcomes, many parents do not read to their young children. One possible explanation for this lack of early literacy practices is mothers' feelings about their ability to successfully read to their children. A series of multiple regressions were used to explore whether new mothers' reading self-efficacy predicted their perceived barriers to reading to their 18-month-old children. Findings suggest that self-efficacy buffers against mother-centered (e.g., too tired), child-centered (e.g., toddler fussy), and structural (e.g., environmental distractions) barriers to reading. Given the importance of early literacy and that not all mothers read to their toddlers, increasing reading self-efficacy may offer a way to reduce perceived barriers to early literacy practices.
\end{abstract}

\section{Introduction}

Researchers and pediatric professionals recommend that children be read to early [1] and often [2]. Research consistently supports the importance of early literacy for a range of beneficial outcomes, such as the development of emergent literacy, reading achievement, and language growth $[2,3]$. Further, children who are read to earlier and more frequently demonstrate greater language ability than their counterparts who are read to later or less frequently [4]. Early increased exposure to print (i.e., children's books) increases children's comprehension and technical reading and spelling skills, which then increase with each year of education after school entry, demonstrating that "skills beget skills" [5]. However, long before kindergarten there are differences in how often children are read to, with low-income children being less likely to engage in shared book reading compared to their wealthier counterparts [6]. Since reading and language abilities predict later school performance [7], reading with children before they enter school is one way parents can promote their children's academic success. Thus, it is crucial to explore what factors may prevent parents from reading to their children.
1.1. Perceived Barriers to Reading. Currently, few studies have explored the barriers that prevent caregivers from reading to their young children. Noteworthy exceptions have identified barriers that can be categorized into three broad domains: parent-centered, child-centered, and structural barriers. Parent-centered barriers include parents' inability to read due to personal feelings, such as being too busy [8] or stressed [9]. Child-centered barriers address children's receptivity and interest, such as being fussy or uninterested in shared book reading [10]. Lastly, structural barriers are situational obstacles, such as not owning books or having a quiet place to read [8]. In addition to these barriers, caregivers' positive beliefs concerning their ability to effectively read to their children may positively contribute to children's differential book exposure in early childhood.

1.2. Maternal Reading Self-Efficacy. Self-efficacy is one's belief in his/her ability to perform a particular behavior successfully [11]. Maternal self-efficacy, which is a mother's belief that she can meet the needs of her child, has been explored in the parenting literature [12]. Mothers with higher self-efficacy have more positive influences on their children's outcomes $[13,14]$; this is likely because mothers' confidence in their 
ability to parent is associated with parenting practices that are conducive to children's healthy development [15]. Given that mothers' performance on various parenting tasks can impact maternal self-efficacy [16], it is reasonable to assume that mothers' perceptions of their ability to engage their children in various educational activities might also influence their perceptions of themselves as parents and their children's subsequent outcomes.

Although research exploring mothers' sense of efficacy for reading to her child, specifically, is lacking, there is a body of work on children's reading self-efficacy and its impact on their motivation to read, which may be relevant. Various studies have shown that children's reading self-efficacy influences seeking or avoiding opportunities to read and the amount of effort exerted when reading [17-19]. Applied to adults, it is reasonable to expect that a mother's reading self-efficacy may similarly influence the frequency of reading to her child or the way she reads to her child.

1.3. Implications for Parent-Child Reading Interactions. It is interesting to consider how mothers' perceived barriers to reading and reading self-efficacy might interact with each other to influence the quality of shared reading with their children. A mother's reading self-efficacy and subsequent motivation to read may interact with the barriers she perceives, with higher reading self-efficacy making her more resilient to perceived barriers and lower self-efficacy allowing perceived barriers to impede reading practices. For example, higher reading self-efficacy may contribute to higher quality reading interactions, while perceived barriers may hinder these high-quality interactions.

Low maternal reading self-efficacy and increased perceptions of barriers to reading may decrease the opportunities for high-quality parent-child reading interactions, which are critical for children's developmental outcomes [20, 21]. Baker et al. [6] found that a positive socioemotional climate during reading resulted in children being more interested in shared book reading and more likely to enjoy these experiences. However, high-quality reading interactions are also beneficial for children's learning outcomes as well. Maternal sensitivity during mother-child reading interactions was significantly related to children's mean level of vocabulary between three years and entry to kindergarten [22]. Further, the language that parents used and the scaffolding that they provided for their children during these reading interactions contributed to their children's learning outcomes as well [23]. Adult elaborations on vocabulary word meanings during book reading contributed to children's deeper understanding of words [24]. Additionally, mothers who used more decontextualized language, asked more labeling questions, and demonstrated greater expressive language had children with higher expressive language scores [25]. These examples highlight how high-quality reading interactions with children can influence children's interest in reading as well as their language development in several ways. Lower maternal reading self-efficacy and perceived barriers to reading may hamper opportunities for children's learning by decreasing opportunities for highquality parent-child reading. Given that we know very little about how maternal reading self-efficacy and perceptions of barriers to reading relate to one another, exploring the relationship between these two variables fills an important gap in the literature.

1.4. Current Study. This study assessed whether higher reading self-efficacy protects against barriers that mothers perceive in reading to their toddlers. While fathers' reading self-efficacy is also worth exploring, as father-child book reading interactions are important and often overlooked, this study only concentrated on mothers' beliefs. Further while addressing the ties between mothers' reading self-efficacy and perceptions of barriers to reading, assessment of the quality of mother-child shared reading interactions was beyond the scope of this study. However, exploring the links between mothers' reading self-efficacy and perceptions of barriers to reading has important implications for mother-child reading quality.

\section{Method}

This study used data from the NICHD-funded Baby Books Project, an intervention study assessing the efficacy of embedding educational information about child development and parenting practices into baby books [26]. All procedures and materials were approved by two university institutional review boards.

2.1. Participants. Participants included 144 first-time, lowincome mothers. The majority were African American (59\%) and had a high school education or less (54\%). Most pregnancies were unplanned (80\%). The background characteristics of mothers shown in Table 1 were measured during pregnancy, and reading self-efficacy and perceived barriers were assessed at 18 months postpartum.

\subsection{Measures}

2.2.1. Background. During the third trimester of pregnancy women were asked about their social, fiscal, and demographic characteristics. Control variables that were used in the analyses included education, race/ethnicity, receipt of public assistance (which served as a proxy for income), marital status, planned pregnancy, prenatal substance use, and maternal age.

2.2.2. Reading Self-Efficacy. Eighteen months postpartum, first-time mothers' self-efficacy for reading was assessed with two questions. (1) How sure are you that you can read to your baby in a way that s/he enjoys? (2) How sure are you that you can keep your baby's attention while reading? Each of the responses was rated on a 4 -point Likert scale $(0=$ not at all sure, 3 = very sure), and the standardized mean of the two items was used. These two items were created using [27] guide to constructing self-efficacy scales and have a correlation of 0.52 .

2.2.3. Perceived Barriers to Reading. At 18 months postpartum, barriers to reading were measured by asking women, 
TABLE 1: Background characteristics of sample $(N=144)$.

\begin{tabular}{lcc}
\hline & $N$ & $\begin{array}{c}\text { Percentage } \\
\text { of sample }\end{array}$ \\
\hline Education & 33 & $23 \%$ \\
$\quad$ Less than high school diploma/GED & 44 & $31 \%$ \\
$\quad$ High school diploma/GED & 67 & $46 \%$ \\
$\quad$ Some college or more & & \\
Race/ethnicity & 85 & $59 \%$ \\
$\quad$ Black, non-Hispanic & 40 & $28 \%$ \\
$\quad$ White, non-Hispanic & 10 & $7 \%$ \\
$\quad$ Hispanic & 9 & $6 \%$ \\
$\quad$ Other & 108 & $75 \%$ \\
Current receipt of public assistance & 24 & $17 \%$ \\
Married/living as married & 29 & $20 \%$ \\
Planned pregnancy & 29 & $20 \%$ \\
Prenatal substance use & & M (SD) \\
\hline$\quad$ & & 23.16 \\
\hline Mother's age (pregnancy) & & $(4.60)$ \\
\hline
\end{tabular}

What are some things that make it hard to read to your baby? Please say "Yes" or "No" to each of these choices. Responses included mother-centered reasons such as feeling too busy, too tired, or forgetting, child-centered reasons such as the baby being sick/tired/fussy, not interested, or too squirmy/restless, and one structural barrier of having too many interruptions/distractions to read. This structural barrier and the mother- and child-centered barriers were used in the analyses individually and as summary scores.

2.3. Analytic Plan. Logistic regressions were run to test the association of reading self-efficacy on each of the individual mother- (too busy, too tired, or forgetting) and child-centered (baby being sick/tired/fussy, not interested, or squirmy/restless) barriers and the one structural barrier of having too many interruptions or distractions. Since there were no differences on key variables based on group assignment, as data were drawn from an intervention study, data from the control and treatment groups were combined and a group condition variable was included in the analysis. Other control variables included maternal education, race, receiving public assistance, marital status, unplanned pregnancy, prenatal substance use, and maternal age.

In order to test the relationship between mothers' reading self-efficacy and perceived barriers to reading, ordinary least squares (OLS) multiple regressions were used with reading self-efficacy as the predictor and the mother-centered barriers and child-centered barriers summary scores as the dependent variables. Additionally, a third OLS multiple regression was used with mothers' reading self-efficacy as the predictor variable and total barriers, which included mother-centered, child-centered, and the structural barrier, as the outcome variable. The same controls as the logistic regressions were used in these analyses.

\section{Results}

On the whole, reading self-efficacy scores were high, suggesting that most women felt confident in their ability to read to their children $(M=2.34$; $\mathrm{SD}=0.52$; observed range $=1-3)$. In considering perceived barriers, $36(25 \%)$ women did not perceive any barriers to reading to their children. Of the remaining 108 (75\%) women, the baby being sick, tired, or fussy (52.8\%) and not interested (43.8\%) were the most commonly identified barriers. Further, mothers were most likely to report child-centered barriers as compared to other types of barriers. Interestingly, mothers' reading self-efficacy scores were more highly correlated with child-centered barriers $(\alpha=-0.36)$, than mother-centered barriers $(\alpha=$ -0.26 ), and had the lowest correlation with structural barriers $(\alpha=-0.15)$. While descriptive analyses demonstrated that mothers who did not perceive any barriers to reading were slightly more educated than mothers who did perceive some barriers to reading, Chi-squared analyses indicated that these two groups of mothers did not significantly differ in their levels of education. The distribution of mothers' perceived barriers to reading can be found in Table 2 .

The logistic regressions shown in Table 3 indicate that although reading self-efficacy was negatively associated with all perceived barriers, reading self-efficacy had the biggest impact on child-centered reasons, particularly whether mothers viewed their child as too squirmy/restless.

Results from the OLS regressions shown in Table 4 demonstrate that women with higher reading self-efficacy perceived fewer barriers to reading. For every 1-point increase in reading self-efficacy, there was a 0.25 -point decrease in mother-centered barriers $(P<0.01)$, a 0.33 -point decrease in child-centered barriers $(P<0.001)$, and a 0.33 -point decrease in all barriers to reading $(P<0.001)$.

\section{Discussion}

The benefits of parents reading to children have been strongly supported through research. Meta-analyses show that the amount of time parents read with their children is related to children's language growth, emergent literacy, and in-school reading achievement [2]. Given the importance of early reading and the findings that many mothers do not initiate reading early [1] or engage in it often [2], reading self-efficacy may help explain these differences. In particular, these results suggest that reading self-efficacy is associated with mothercentered, child-centered, and structural barriers to reading, and perhaps efficacy can buffer against perceived barriers. These findings are important because overcoming barriers and promoting early reading are important for helping to develop children's language and literacy skills. For example, Harris and colleagues [8] showed that parental self-efficacy in selecting appropriate children's books was associated with having more books, reporting fewer reading barriers, and perceiving more benefits of reading. This study extends these findings by connecting perceptions of mothers' ability to read to their children in an interesting and enjoyable way to various perceived barriers to reading. 
TABLE 2: Distribution of reasons that make it hard to read to one's child.

\begin{tabular}{|c|c|c|c|c|}
\hline & \multicolumn{4}{|c|}{ Mother-centered reasons } \\
\hline & Too busy & Too tired & Forgot & Total mother-centered reasons \\
\hline $\mathrm{M}(\mathrm{SD})$ & $0.23(0.42)$ & $0.28(0.45)$ & $0.24(0.43)$ & $0.76(1.01)$ \\
\hline \multirow[t]{3}{*}{ Range } & $0-1$ & $0-1$ & $0-1$ & $0-3$ \\
\hline & \multicolumn{4}{|c|}{ Child-centered reasons } \\
\hline & Baby sick, tired, or fussy & Baby not interested & Baby too squirmy/restless & Total child-centered reasons \\
\hline $\mathrm{M}(\mathrm{SD})$ & $0.53(0.50)$ & $0.44(0.50)$ & $0.40(0.49)$ & $1.37(1.22)$ \\
\hline \multirow[t]{3}{*}{ Range } & $0-1$ & $0-1$ & $0-1$ & $0-3$ \\
\hline & \multicolumn{4}{|c|}{ Structural reason } \\
\hline & \multicolumn{4}{|c|}{ Too many interruptions/distractions } \\
\hline $\mathrm{M}(\mathrm{SD})$ & \multicolumn{4}{|c|}{$0.32(0.48)$} \\
\hline \multirow[t]{3}{*}{ Range } & \multicolumn{4}{|c|}{$0-2$} \\
\hline & \multicolumn{4}{|c|}{ Total barriers } \\
\hline & \multicolumn{4}{|c|}{ Sum of mother, child, and structural reasons } \\
\hline $\mathrm{M}(\mathrm{SD})$ & \multicolumn{4}{|c|}{$2.44(2.23)$} \\
\hline Range & \multicolumn{4}{|c|}{$0-7$} \\
\hline
\end{tabular}

TABLE 3: Reading self-efficacy predicting reasons that make it hard to read to one's child (odds ratio).

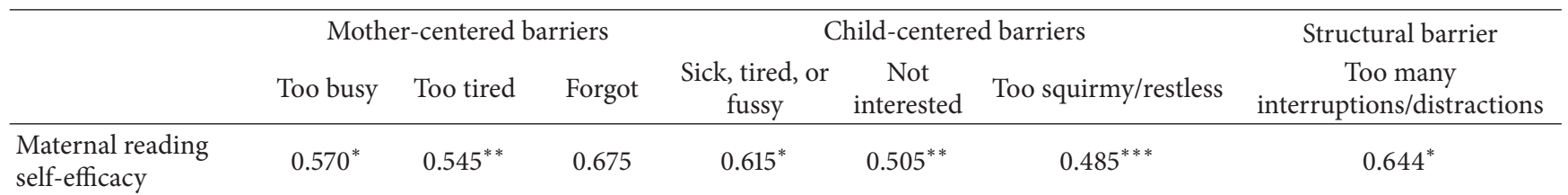

Note: Exponentiated coefficients; covariates include receipt of public assistance, married/living as married, prenatal substance use, education, race, and mother's age; ${ }^{*} P<0.05 ;{ }^{* *} P<0.01 ;{ }^{* * *} P<0.001$.

4.1. Reading Self-Efficacy Scores. Mothers in this sample reported a relatively high level of reading self-efficacy $(M=$ 2.34; $\mathrm{SD}=0.52$; observed range $=1-3)$. These data were collected for the Baby Books Project, which assessed the efficacy of embedding educational information about child development and parenting practices into baby books. Pregnant women who agreed to participate in a "Baby Books" study may place a high value on reading to young children. Thus, selection processes may have identified a sample of mothers whose reading self-efficacy scores may not necessarily be generalizable to other mothers. Another potential explanation for these high levels of reading selfefficacy could be that since these books increased mothers' parenting self-efficacy overall [13], they may have influenced women's perceptions of themselves as being effective readers with their children, or vice versa.

4.1.1. Reading Self-Efficacy and Perceived Barriers. In our descriptive analyses we found that mothers' reading selfefficacy scores were most highly correlated with childcentered barriers to reading $(\alpha=-0.36)$ (mother-centered $\alpha=-0.26$; structural barriers $\alpha=-0.15$ ). Correlations between maternal reading self-efficacy and individual childbarriers are as follows: sick, tired, or fussy $(\alpha=-0.25)$, not interested ( $\alpha=-0.33)$, and too squirmy/restless $(\alpha=$ $-0.31)$. A possible explanation for the higher correlations between mothers' reading self-efficacy and child-centered barriers, in particular for the child not being interested or being too squirmy/restless, may be due to beliefs that mothers' inability to effectively read to children contributes directly to these barriers. For example, structural barriers may exist regardless of whether or not a mother feels she is an effective reader. Similarly, mothers being too busy, too tired, or forgetting to read are probably not due to mothers being ineffective readers either. However, a mother's ability to read to her child may directly contribute to how interested and how squirmy/restless her child is; it could also be the case that these child behaviors are actually influencing mothers' perceptions of how effective she is as a reader. Although the direction of influence for mothers' reading self-efficacy and child-centered barriers to reading is unclear, these two constructs exhibit the highest correlations of all barriers to reading.

4.2. Mother-Child Reading Interactions. The findings of this study demonstrating links between barriers to reading and maternal reading self-efficacy likely contribute to the quality of parent-child interactions during reading, which can impact children's literacy outcomes [10, 22]. Improving maternal reading self-efficacy may be a promising way not only to reduce perceived barriers to reading and facilitate more frequent and higher quality reading, but also improve the affective and emotional quality of shared interactions during reading. While research has not explicitly explored whether maternal reading self-efficacy and mothers' affective quality during reading are linked, self-efficacy research in 
TABLE 4: Reading self-efficacy predicting reason that makes it hard to read (OLS).

\begin{tabular}{lccc}
\hline & Mother-centered barriers & Child-centered barriers & ${ }^{\mathrm{a}}$ Total barriers \\
& $\beta(\mathrm{SE})$ & $\beta(\mathrm{SE})$ & $\beta(\mathrm{SE})$ \\
\hline Maternal reading self-efficacy & $-0.25^{* *}(0.08)$ & $-0.33^{* * *}(0.08)$ & $-0.33^{* * *}(0.08)$ \\
\hline
\end{tabular}

Note: Standard errors are in parentheses; standardized regression coefficients are displayed; covariates include receipt of public assistance, married/living as married, prenatal substance use, education, race, and mother's age; the singular structural barrier was not included because it is a dichotomous variable; ${ }^{* *} P<$ $0.01 ;{ }^{* * *} P<0.001$.

${ }^{a}$ Total barriers include mother-centered, child-centered, and the singular structural barrier.

other domains demonstrates that this is probable. Considering that higher self-efficacy on a particular task is associated with greater enjoyment of the task [28], if mothers feel efficacious in reading to their children they may enjoy reading more, thereby creating a more positive socioemotional climate when they read to their children. They may also be less likely to provide negative feedback, restrict, or discipline their child and display increased levels of sensitivity, all of which increase the quality of shared reading interactions [20,22].

4.3. Limitations. Although these findings are promising and demonstrate a correlational relationship between mothers' reading self-efficacy and their perceived barriers to reading, a causal relationship between these two variables cannot be inferred. Since reading self-efficacy and perceived barriers were measured at the same time, the direction of the effect is unclear. Additionally, given that maternal reading selfefficacy and maternal perceptions of barriers to reading were both self-reported, these findings may reflect sharedmethod variance. Further, the use of only two questions to measure maternal reading self-efficacy is another limitation. Although mothers were asked other questions about reading to their children, only the two questions included in this study addressed their perceptions of their ability to effectively read to their children. Questions that were omitted from this study included "How easy is it to find or make time to read to your baby" and "How comfortable are you with reading to your baby in public places," which do not necessarily relate to mothers' abilities as effective readers and may tap into external barriers to reading. Lastly, these data were collected with low-income primiparous mothers and findings may not generalize to other types of parents such as fathers or mothers with higher incomes or more children.

4.4. Future Directions. Although these findings demonstrate a relationship between low-income mothers' reading selfefficacy and their perceived barriers to reading, future studies can expand on these findings. Given that this study demonstrated a correlational relationship between maternal reading self-efficacy and perceived barriers to reading, future research should experimentally manipulate reading self-efficacy to test whether different levels of this variable impact perceived barriers and actual reading practices. Further, since questionnaire data were used to measure both reading self-efficacy and perceived barriers to reading, studies exploring this relationship should utilize other methods of data collection and not rely solely on mothers' self-reports. Moreover, the self-efficacy measure used in this study only consisted of two items; research addressing maternal reading self-efficacy in the future should use additional items to measure how effective mothers feel about their ability to read to their children, thereby strengthening the measurement of maternal reading self-efficacy. Also, considering that only a few barriers were assessed in this study, it would be useful for future studies exploring maternal barriers to reading to utilize qualitative interviews to identify additional barriers that are not cited in the literature. It would also be interesting to assess how mothers' perceived barriers to reading actually impact their time spent reading with their children. Future research could consider employing electronic trackers to more accurately measure how long mothers spend reading to their children. Lastly, given that parenting research as a whole largely focuses on mothers, it is especially important that future studies explore how fathers' reading beliefs might also influence their reading behaviors with their children.

\section{Conclusions}

Previous research supports the importance of reading efficacy $[18]$ and barriers $[8,9]$, with few connecting these constructs together. The findings from this study highlight the relationship between reading self-efficacy and perceived barriers to reading for mothers with very young children. In particular, these findings demonstrate that reading self-efficacy was negatively associated with all perceived barriers. However, reading self-efficacy had the biggest impact on child-centered reasons, particularly whether mothers viewed their child as too squirmy/restless. Further, women with higher reading self-efficacy perceived fewer barriers to reading. Since reading with young children is one of the best ways to promote literacy, language skills, and school readiness, these findings identify a relationship worthy of further exploration.

\section{Conflict of Interests}

The authors declare that there is no conflict of interests regarding the publication of this paper.

\section{Acknowledgment}

Funding was provided by NICHD (RO1HD047749-01A1).

\section{References}

[1] P. C. High, L. LaGasse, S. Becker, I. Ahlgren, and A. Gardner, "Literacy promotion in primary care pediatrics: can we make a difference?” Pediatrics, vol. 105, no. 4, pp. 927-934, 2000. 
[2] A. G. Bus, M. H. van IJzendoorn, and A. D. Pellegrini, "Joint book reading makes for success in learning to read: a metaanalysis on intergenerational transmission of literacy," Review of Educational Research, vol. 65, no. 1, pp. 1-21, 1995.

[3] C. Crain-Thoreson and P. S. Dale, "Do Early talkers become early readers? Linguistic precocity, preschool language, and emergent literacy," Developmental Psychology, vol. 28, no. 3, pp. 421-429, 1992.

[4] C. J. Dunst, A. Simkus, and D. W. Hamby, "Relationship between age of onset and frequency fo reading and infants' and toddlers' early language and literacy development," CELL Review, vol. 5, no. 3, pp. 1-10, 2012.

[5] S. E. Mol and A. G. Bus, "To read or not to read: a metaanalysis of print exposure from infancy to early adulthood," Psychological Bulletin, vol. 137, no. 2, pp. 267-296, 2011.

[6] L. Baker, D. Scher, and K. Mackler, "Home and family influences on motivations for reading," Educational Psychologist, vol. 32, no. 2, pp. 69-82, 1997.

[7] G. J. Duncan, C. J. Dowsett, A. Claessens et al., "School Readiness and Later Achievement," Developmental Psychology, vol. 43, no. 6, pp. 1428-1446, 2007.

[8] K. K. Harris, J. J. Loyo, C. K. Holahan, R. Suzuki, and N. H. Gottlieb, "Cross-sectional predictors of reading to young children among participants in the Texas WIC program," Journal of Research in Childhood Education, vol. 21, no. 3, pp. 254-268, 2007.

[9] J. Karrass, M. C. VanDeventer, and J. M. Braungart-Rieker, "Predicting shared parent-child book reading in infancy," Journal of Family Psychology, vol. 17, no. 1, pp. 134-146, 2003.

[10] C. Bergin, “The parent-child relationship during beginning reading," Journal of Literacy Research, vol. 33, no. 4, pp. 681-706, 2001.

[11] A. Bandura, "Self-efficacy: toward a unifying theory of behavioral change," Psychological Review, vol. 84, no. 2, pp. 191-215, 1977.

[12] P. K. Coleman and K. H. Karraker, "Maternal self-efficacy beliefs, competence in parenting, and toddlers' behavior and developmental status," Infant Mental Health Journal, vol. 24, no. 2, pp. 126-148, 2003.

[13] A. S. Albarran and S. M. Reich, "Using baby books to increase new mothers' self-efficacy and improve toddler language development," Infant and Child Development, vol. 23, no. 4, pp. 374387, 2014.

[14] C. Izzo and L. Weiss, "Parental self-efficacy and social support as predictors of parenting practices and children's socioemotional adjustment in Mexican immigrant families," Journal of Prevention and Intervention in the Community, vol. 20, no. 1-2, pp. 197213, 2000.

[15] T. L. Jones and R. J. Prinz, "Potential roles of parental selfefficacy in parent and child adjustment: a review," Clinical Psychology Review, vol. 25, no. 3, pp. 341-363, 2005.

[16] A. Bandura, Social Foundations of Thoughts \& Action: A Social Cognitive Theory, Prentice Hall, England Cliffs, NJ, USA, 1986.

[17] K. L. Lau, "Reading motivation, perceptions of reading instruction and reading amount: a comparison of junior and senior secondary students in Hong Kong," Journal of Research in Reading, vol. 32, no. 4, pp. 366-382, 2009.

[18] K. E. Stanovich, "Matthew effects in reading: some consequences of individual differences in the acquisition of literacy," Reading Research Quarterly, vol. 21, no. 4, pp. 360-407, 1986.
[19] A. Wigfield and J. T. Guthrie, "Relations of children's motivation for reading to the amount and breadth of their reading," Journal of Educational Psychology, vol. 89, no. 3, pp. 420-432, 1997.

[20] A. G. Bus and M. H. van Ijzendoorn, "Affective dimension of mother-infant picturebook reading," Journal of School Psychology, vol. 35, no. 1, pp. 47-60, 1997.

[21] S. H. Landry, K. E. Smith, P. R. Swank, T. Zucker, A. D. Crawford, and E. F. Solari, "The effects of a responsive parenting intervention on parent-child interactions during shared book reading," Developmental Psychology, vol. 48, no. 4, pp. 969-986, 2012.

[22] J. Roberts, J. Jurgens, and M. Burchinal, "The role of home literacy practices in preschool children's language and emergent literacy skills," Journal of Speech, Language, and Hearing Research, vol. 48, no. 2, pp. 345-359, 2005.

[23] K. L. Fletcher and E. Reese, "Picture book reading with young children: a conceptual framework," Developmental Review, vol. 25, no. 1, pp. 64-103, 2005.

[24] M. D. Coyne, D. B. McCoach, S. Loftus, R. Zipoli Jr., and S. Kapp, "Direct vocabulary instruction in kindergarten: teaching for breadth versus depth," The Elementary School Journal, vol. 110, no. 1, pp. 1-18, 2009.

[25] P. R. Britto, J. Brooks-Gunn, and T. M. Griffin, "Maternal reading and teaching patterns: associations with school readiness in low-income African American families," Reading Research Quarterly, vol. 41, no. 1, pp. 68-89, 2006.

[26] S. M. Reich, L. Bickman, B. R. Saville, and J. Alvarez, "The effectiveness of baby books for providing pediatric anticipatory guidance to new mothers," Pediatrics, vol. 125, no. 5, pp. 9971002, 2010.

[27] A. Bandura, "Guide for constructing self-efficacy scales," in SelfEfficacy Beliefs of Adolescents, F. Pajares and T. Urdan, Eds., vol. 5, pp. 307-337, Information Age Publishing, Greenwich, Conn, USA, 2006.

[28] L. Hu, R. W. Motl, E. McAuley, and J. F. Konopack, "Effects of self-efficacy on physical activity enjoyment in college-aged women," International Journal of Behavioral Medicine, vol. 14, no. 2, pp. 92-96, 2007. 

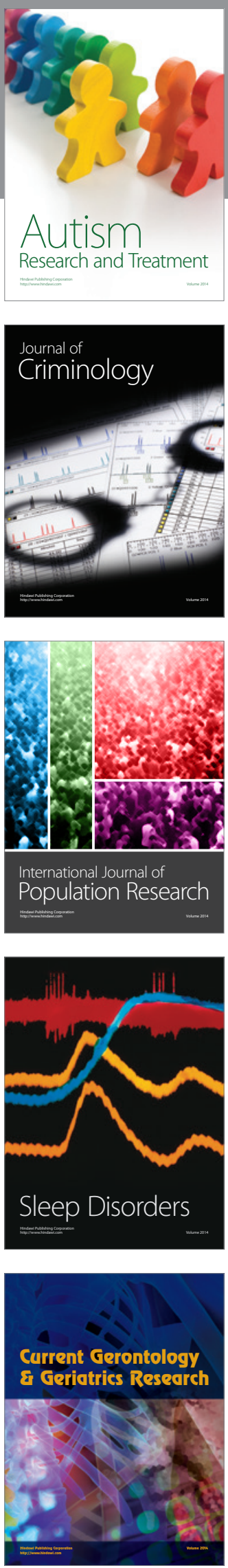
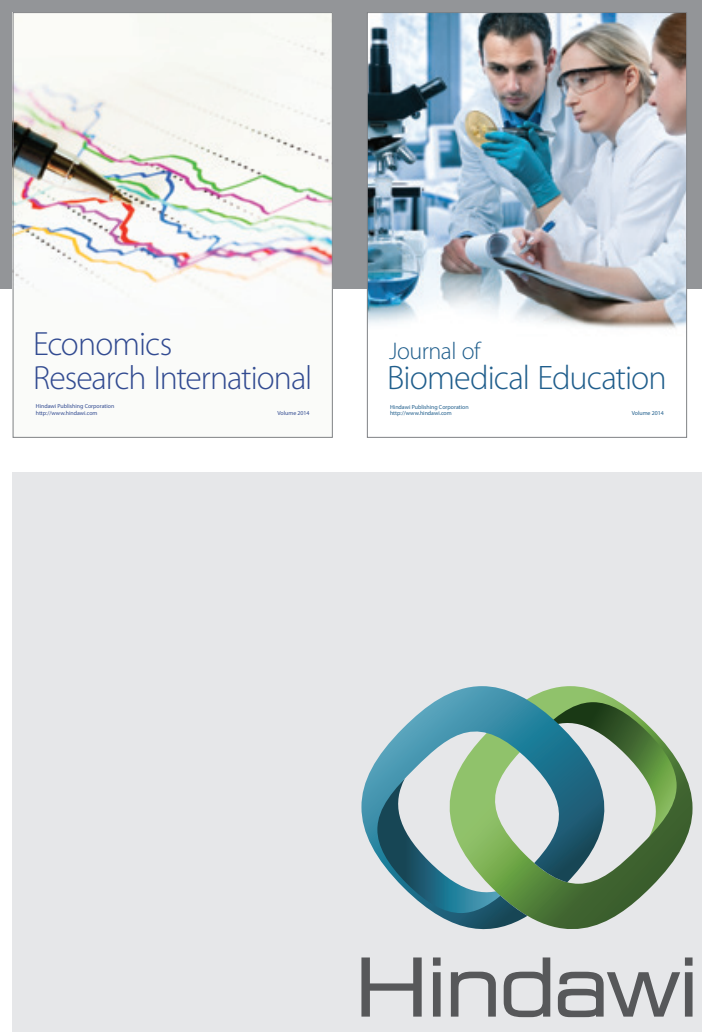

Submit your manuscripts at

http://www.hindawi.com
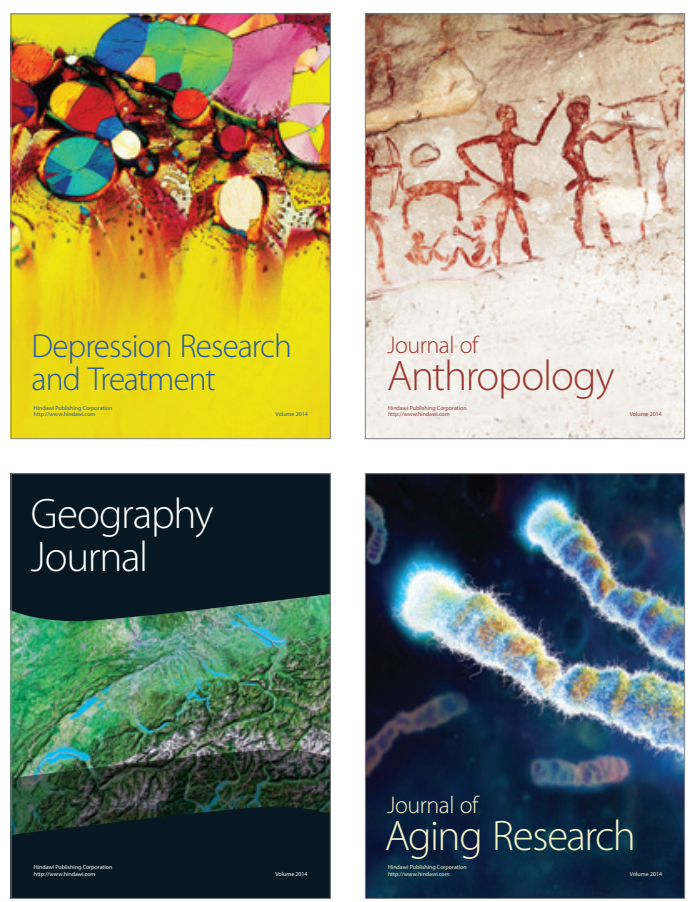
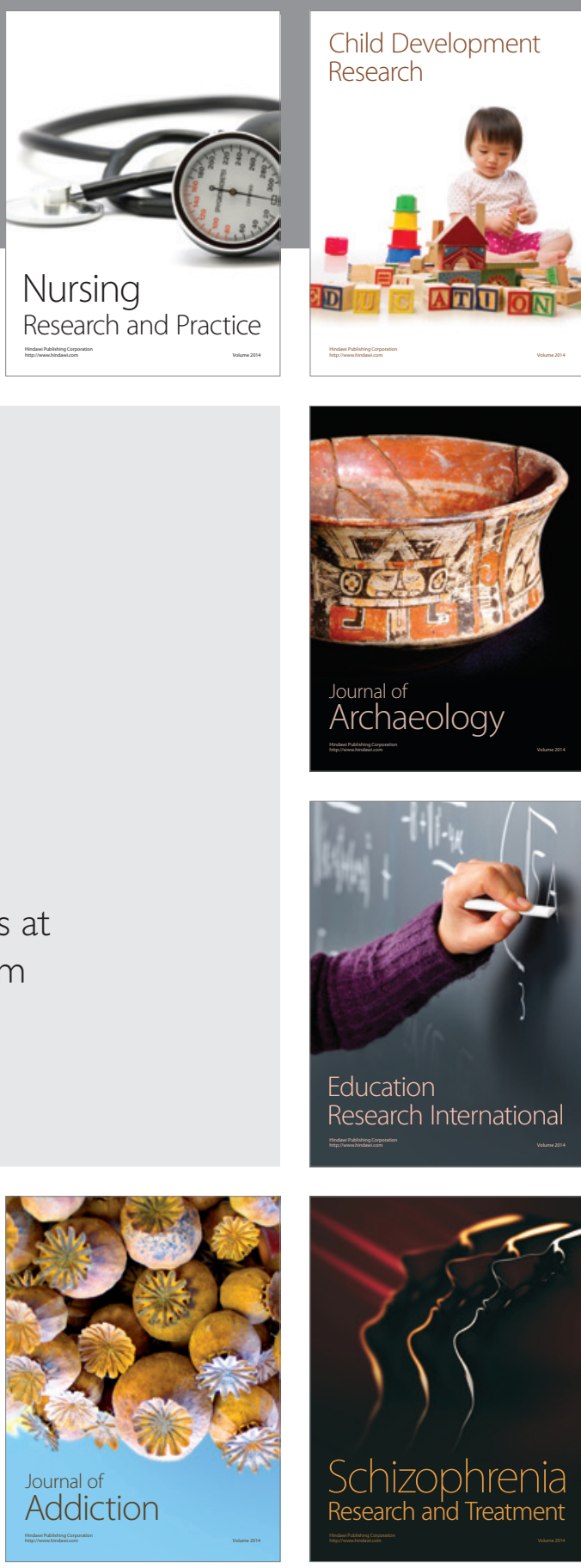

(D)
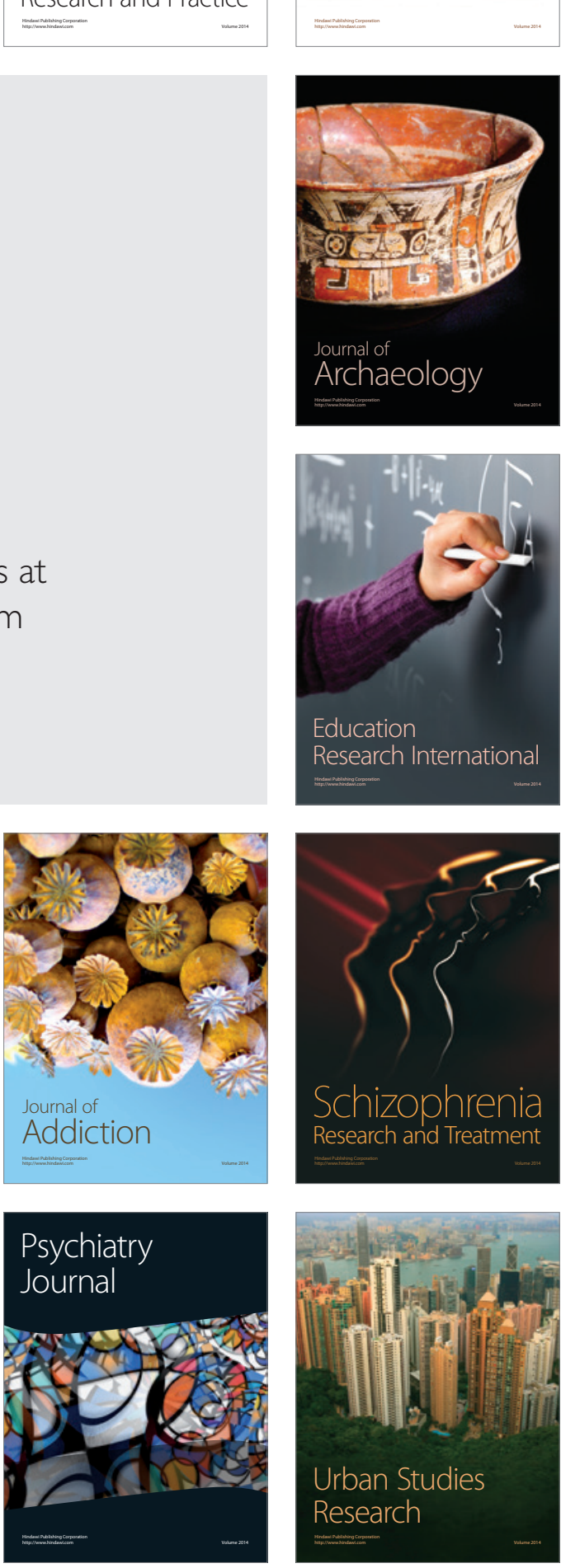